\title{
Pseudaspidimerus palatus, a new species of the genus Pseudaspidimerus Kapur, 1948 from the Malay Peninsula (Coleoptera, Coccinellidae)
}

\author{
Lizhi Huo', Wenjing Li', Xingmin Wang' \\ I Key Laboratory of Bio-Pesticide Innovation and Application, Engineering Technology Research Center of \\ Agricultural Pest Biocontrol, Guangdong Province; College of Agriculture, South China Agricultural University, \\ Guangzhou 510640, China
}

Corresponding author: Xingmin Wang (wangxmcn@scau.edu.cn)

Academic editor: M. Thomas | Received 24 June 2017 | Accepted 22 August 2017 | Published 4 October 2017

http://zoobank.org/9877BFDD-5856-4452-8F0C-11258ECCD6D9

Citation: Huo L, Li W, Wang X (2017) Pseudaspidimerus palatus, a new species of the genus Pseudaspidimerus Kapur, 1948 from the Malay Peninsula (Coleoptera, Coccinellidae). ZooKeys 706: 109-115. https://doi.org/10.3897/ zookeys.706.18081

\begin{abstract}
A new species of the genus Pseudaspidimerus Kapur, 1948 (Coleoptera: Coccinellidae), Pseudaspidimerus palatus Huo \& Wang, sp. n. from the Malay Peninsula is described with illustrations and a distribution map. The genus Pseudaspidimerus is recorded for the first time from Malaysia and Singapore.
\end{abstract}

\section{Keywords}

Aspidimerini, lady beetles, new record, Malaysia, Singapore

\section{Introduction}

Pseudaspidimerus Kapur is a small genus of the tribe Aspidimerini Weise, 1900, with only ten species described until now (Poorani 2001; Huo et al. 2014). Species of this genus mostly prey on aphids, mealybugs, scale insects, and whiteflies, and are important natural enemies of economically important pests of various crops (Poorani 2001; Basu and Patro 2007; Megha et al. 2015). Kapur (1948) established this genus based on its parallel prosternal carinae forming a rectangular area (Fig $2 \mathrm{~b}$ ) and its robust

Copyright Lizhi Huo et al. This is an open access article distributed under the terms of the Creative Commons Attribution License (CC BY 4.0), which permits unrestricted use, distribution, and reproduction in any medium, provided the original author and source are credited. 
penis (Fig. 1g), which are the most important generic characters. During the course of our study of borrowed specimens from different repositories, a new species of this genus was discovered from the Malay Peninsula. This is the first record of the genus Pseudaspidimerus from Malaysia and Singapore.

\section{Materials and methods}

All studied materials were borrowed from the following museums:

HNHM Hungarian Natural History Museum, Budapest, Hungary;

MIZ Museum and Institute of Zoology PAS, Warsaw, Poland;

NMPC Natural History Museum, Prague, Czech Republic.

Type specimens are deposited in the above museums, except two paratypes kept in South China Agricultural University (SCAU).

Dry specimens were softened in $70^{\circ} \mathrm{C}$ water for 12 hours; the abdomen was detached and cleared in warm $10 \% \mathrm{KOH}$ solution for $1-2$ hours. Genitalia of both sexes were dissected, rinsed with distilled water, transferred to glycerol, and examined on slides. Genitalia images were photographed with digital cameras (Axiocam 506 color) connected to the microscope (ZEISS Imager M2). The software ZEN 2.3 was used to capture genitalia images.

External morphology was observed with a stereomicroscope (SteREO Discovery V20, Zeiss). Images were photographed with digital cameras (AxioCam HRc) connected to the microscope. Measurements were made using the measurement tools of the software AxioVision Rel. 4.8. The following abbreviations are used in the description:

TL total length, from apical margin of clypeus to apex of elytra;

TW total width, across both elytra at widest part;

TH total height, through the highest point of elytra to metaventrite;

HW head width, including eyes;

PL pronotal length, from the middle of anterior margin to the base of pronotum;

PW pronotal width at widest part;

EL elytral length, along the suture, from the apex to the base including the scutellum;

EW elytral width, across both elytra at widest part;

ID interocular distance, nearest distance between eyes.

Scanning electron micrographs were made using HITACHI S-3400N in the Electron Microscopy Laboratory of the MIZ. The distribution map was downloaded from a free map website (http://alabamamaps.ua.edu) and all images were cleaned up and laid out in plates with Adobe Photoshop CS5. Morphological terms follow Ślipiński and Tomaszewska (2010). 


\section{Taxonomy}

Pseudaspidimerus palatus Huo \& Wang, sp. n. http://zoobank.org/7961DD3D-2423-42E1-A7E5-35C53C0A4612 Figures 1-3

Types. Holotype: $1 \delta^{\lambda}$, “Thailand, Ranong prov. Ban Na env., 22-26.III.1996, 9³4'N, $98^{\circ} 42^{\prime} \mathrm{E}, \mathrm{K}$ Majer leg" (NMPC); Paratypes (5): 2 \%, "S Thailand, Betong Gunung Cang dun vill., Yala dist., 25.3.-22.4.1993, J. Horák leg" (NMPC, SCAU); 20 , "Singapore, 29 Dr. Baum” (MIZ, SCAU); 1 ㅇ, "Malacca Biró/ Kwala-Lumpur/” (HNHM).

Diagnosis. Elytra black with apical part yellowish brown, maculae oblique expending from apical $1 / 3$ of suture to lateral $1 / 2$ length of lateral margin; Penis extremely robust, arcuate, swollen anteriorly with small inner branch, narrowest at middle; Penis guide, in lateral view, widest at base, gradually narrowing to pointed apex. In ventral view, shovel shaped, only a little longer than broad, slightly narrowing to basal $1 / 3$, thence gradually narrowing to small rounded apex.

Description. TL: $1.91-2.07 \mathrm{~mm}$, EL: $1.43-1.49 \mathrm{~mm}$, TW: $1.56-1.66 \mathrm{~mm}, \mathrm{TH}$ : 1.00-1.06 mm, PL: 0.64-0.73 mm, PW: $1.13-1.25 \mathrm{~mm}, \mathrm{HW}: 0.76-0.81 \mathrm{~mm}$, ID: 0.40-0.43 mm, TL/TW: 1.22-1.25, PL/PW: 0.57-0.58, EL/EW: 0.90-0.92, HW/ PW: 0.65-0.67, PW/EW: 0.72-0.75, ID/HW: 0.53.

Body oblong oval, densely covered with short, silvery white pubescence (Fig. 1a). Head yellow in male (Fig. 1b) and black in female. Pronotum black with anterior margin narrowly reddish brown and ante-lateral corners with a small triangular yellow spot. Elytra black with apical part yellowish brown, maculae oblique expending from apical $1 / 3$ of suture to lateral $1 / 2$ length of lateral margin. Underside dark brown to black except mouthpart, prothoracic hypomeron, and legs yellow. Mentum dark brown. Posterior margin of ventrite 6 strongly emarginate in male and broadly rounded in female (Fig. 1d-e). Punctures on frons fine and dense, 0.5-1.0 diameters apart; on elytra and pronotum sparse, 1.0-2.0 diameters apart; on metaventrite fine and sparse on middle part, coarse and densely distributed laterally (Fig. 2a). Ventral surface with short, dense, silvery pubescence.

Male genitalia. Penis extremely robust, arcuate, swollen anteriorly with small inner branch, narrowest at middle (Fig. 1g). Tegminal strut slightly shorter than main part of tegmen. Parameres slightly longer than phallobase length and a little shorter than penis guide, apex with long sparse setae (Fig. 1h). Penis guide, in lateral view, widest at base, gradually narrowing to pointed apex. In ventral view, shovel shaped, only a little longer than broad, slightly narrowing to basal $1 / 3$, thence gradually narrowing to small rounded apex (Fig. 1i).

Female genitalia. Coxites fairly broad, 0.5 times as long as wide, with a projection on basal end, apical and outer margin with dense, long setae. Spermatheca curved, Cshaped, ramus and nodulus not clearly differentiated (Fig. 1f).

Distribution. Thailand (Ranong, Yala), Malaysia (Kuala Lumpur), Singapore. 

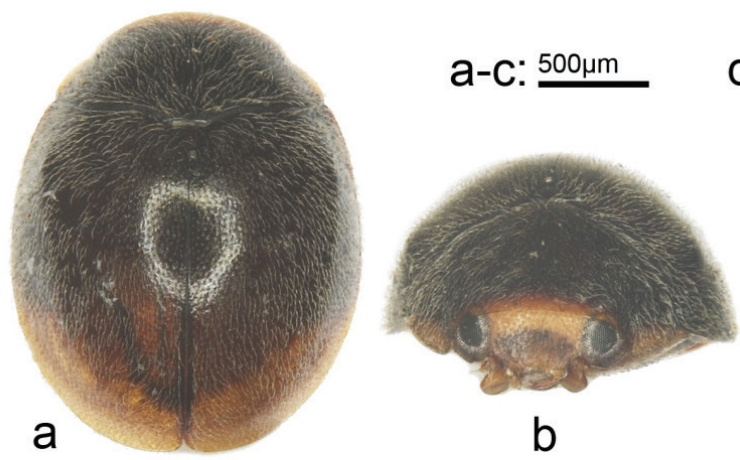

d,e: $\underline{200 \mu m} \quad f-i: \underline{100 \mu m}$
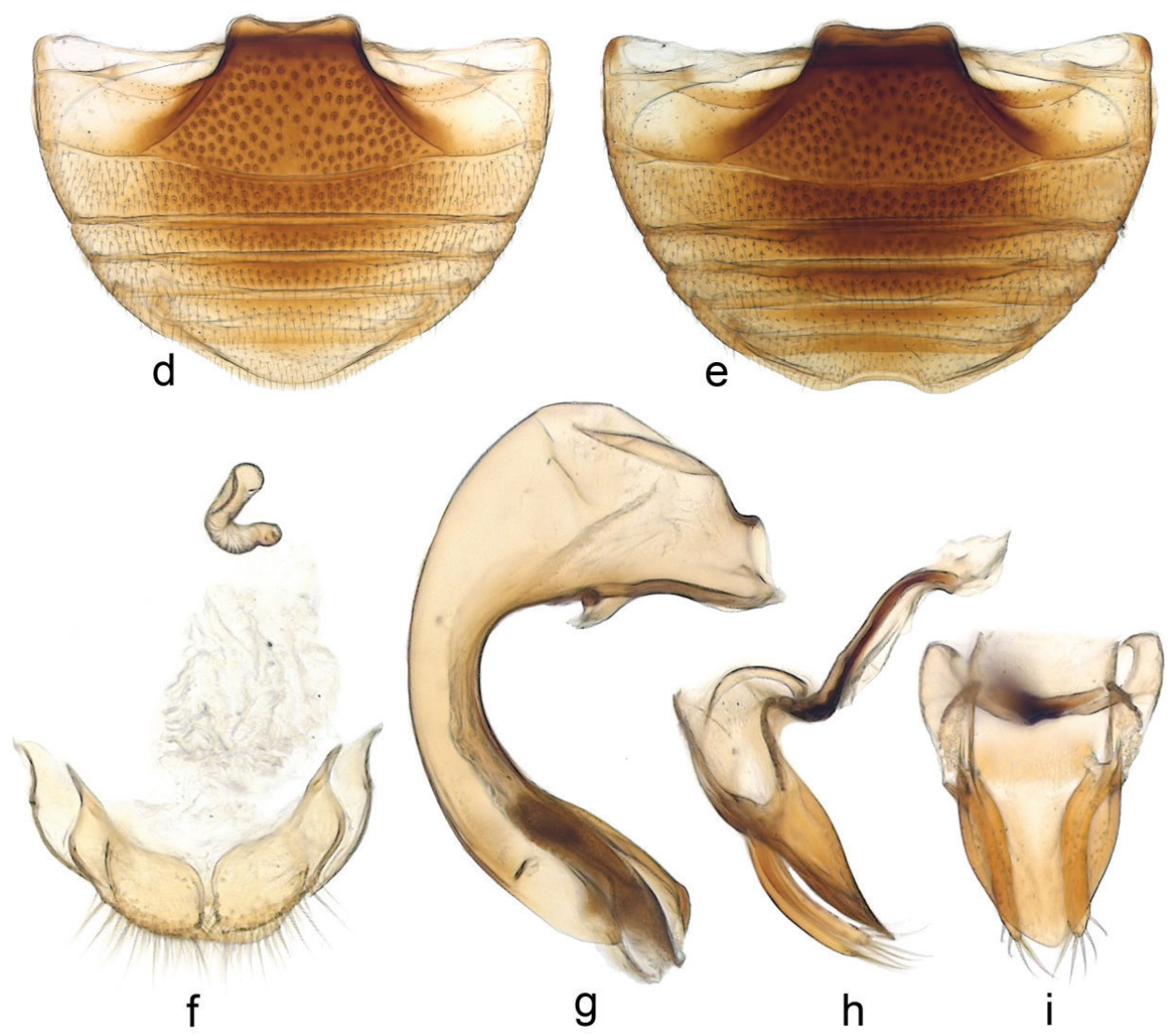

Figure I. Pseudaspidimerus palatus Huo \& Wang sp. n. a dorsal view b frontal view c lateral view $\mathbf{d}$ female abdomen $\mathbf{e}$ male abdomen $\mathbf{f}$ female genitalia $\mathbf{g}$ penis $\mathbf{h}$ lateral view of tegmen $\mathbf{i}$ ventral view of tegmen.

Remarks. In general appearance, this species is similar to a variation of $P$. mauliki (Huo et al. 2014, Fig. 2e) with elytral apical third with an oblique yellowish brown spot laterally extending up to nearly the half length of elytra. The penis of male genitalia is also very similar to that of $P$. mauliki (Huo et al. 2014, Fig. 2j): penis extremely robust, arcuate, 


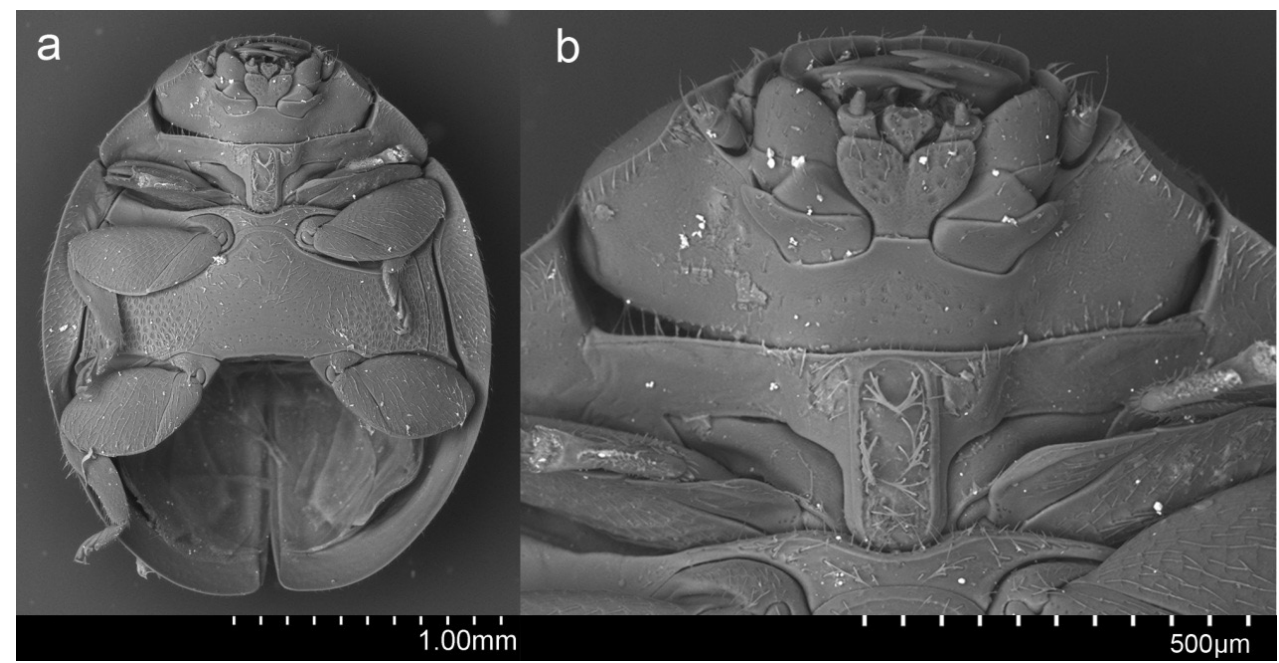

Figure 2. Pseudaspidimerus palatus Huo et Wang sp. n. a ventral view b prosternum and mouth part.

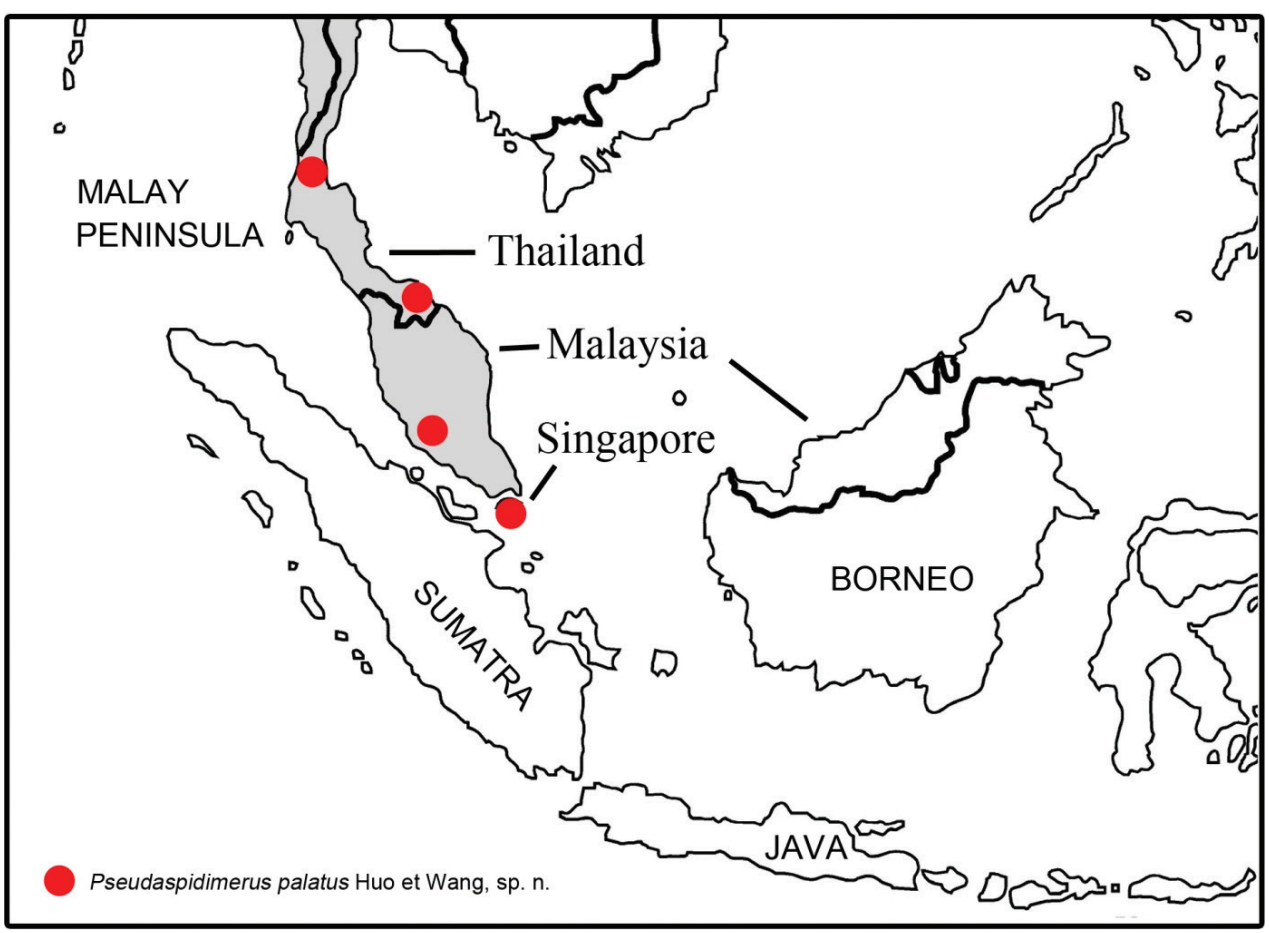

Figure 3. Distribution map of Pseudaspidimerus palatus Huo \& Wang, sp. n.

swollen anteriorly with a small inner branch, narrowest at middle. The only difference is the ventral view of penis guide. In $P$. mauliki, penis guide is about 1.2 times as long as broad at base, widest at basal third and then gradually narrowing to a fairly broad apex, which is weakly emarginate at middle (Huo et al. 2014, Fig. 2k). In P. palatus, penis guide is shovel 
shaped, only a little longer than broad, widest at basal third, gradually narrowed thereafter to a rounded apex. The shape of the penis guide is also close to that of $P$. lambai Kapur, 1967 and P. flaviceps (Walker, 1859). In P. lambai and P. flaviceps, penis guide is more slender in lateral view and longer in ventral view, and about two times as long as broad.

Etymology. The specific name is derived from the Latin noun "pala" and postfix "-atus", referring to that its penis guide looks like a shovel in ventral view.

\section{Acknowledgements}

We thank Wioletta Tomaszewska (MIZ), Jiří Hájek (NMPC) and Ottó Merkl (HNHM) for their help during the author's (Lizhi Huo) visit to the museums. Magdalena Kowalewska-Groszkowska (MIZ) helped with SEM photographs. We are grateful to J. Poorani (National Research Centre for Banana, Trichy) for suggestions during the identification. The research was supported by the National Natural Science Foundation of China (31501884), Science and Technology Planning Project of Guangdong Province (2015A030302069 and 2017A020208060) and Science and Technology Program of Guangzhou, China (201509010023).

\section{References}

Basu M, Patro B (2007) New records of host plants and natural enemies of Aphis citricola van der Goot (Aphididae: Homoptera) from Orissa. India Journal of Entomological Research 31(2): 165-168.

Huo LZ, Wang XM, Chen XS, Ren SX (2014) The genus Pseudaspidimerus Kapur, 1948 (Coleoptera: Coccinellidae) from Laos, with descriptions of two new species. The Pan-Pacific Entomologist 90(4): 182-190. http://dx.doi.org/10.3956/2014-90.4.182

Kapur AP (1948) A revision of the tribe Aspidimerini Weise (Coleoptera, Coccinellidae). Transactions of the Royal Entomological Society of London 99: 77-128. https://doi. org/10.1111/j.1365-2311.1948.tb01233.x.

Kapur AP (1967) The Coccinellidae (Coleoptera) of the Andamans. Proceedings of the National institute of Sciences of India 32(B): 148-189.

Megha RR, Vastrad AS, Kamanna BC, Kulkarni NS (2015) Species complex of coccinellids in different crops at Dharwad region. Journal of Experimental Zoology (India) 18(2): 931-935.

Poorani J (2001) A review of the genus Pseudaspidimerus Kapur (Coleoptera: Coccinellidae) from the Indian subregion with description of a new species. Oriental Insects 35: 299-310. http://dx.doi.org/10.1080/00305316.2001.10417309

Ślipiński A, Tomaszewska W (2010) Coccinellidae Latreille, 1802. In: Leschen RAB, Beutel RG, Lawrence JF (Eds) Handbook of Zoology, 2, Coleoptera. Walter de Gruyter GmbH $\&$ Co KG, Berlin, New York, 454-472.

Walker F (1859) Characters of some apparently undescribed Ceylon insects. Annals and Magazine of Natural History 4: 217-224. 


\section{Supplementary material I}

\section{Table of localities}

Authors: Lizhi Huo, Wenjing Li, Xingmin Wang

Data type: occurence

Copyright notice: This dataset is made available under the Open Database License (http://opendatacommons.org/licenses/odbl/1.0/). The Open Database License $(\mathrm{ODbL})$ is a license agreement intended to allow users to freely share, modify, and use this Dataset while maintaining this same freedom for others, provided that the original source and author(s) are credited.

Link: https://doi.org/10.3897/zookeys.706.18081.suppl1 